\title{
PATTERN OF PSYCHIATRIC INPATIENT ADMISSION IN IBADAN: IMPLICATIONS FOR SERVICE ORGANISATION AND PLANNING
}

\author{
Olayinka Atilola $^{1}$ and Funmilayo Olayiwola ${ }^{2}$ \\ 1. Senior Registrar, Dept of Psychiatry, University College Hospital Ibadan, Nigeria. \\ 2. Nursing Officer, Nursing Services Division, University College Hospital Ibadan, Nigeria.
}

Correspondence:

Dr. Olayinka Atilola

Department of Psychiatry

University College Hospital

Ibadan

E-mail: draromedics@yahoo.com

$+234-8063867269$

\begin{abstract}
Introduction: Reports from different parts of the world has shown a seasonal pattern in psychiatric admission. Seasonal changes in climatic and social situations have been attributed. Such audit of psychiatric services is not a popular research venture in Nigeria.

Objectives: The study aims to describe the pattern of old psychiatric admissions in a tertiary health facility and the socio-cultural and environmental factors that may influence the pattern.

Methods: Data on monthly admissions over a 5-year period were extracted from the admission and discharge records kept by the nursing services unit. The data was processed using Microsoft excel and the pattern over the 5-year period was examined using graphical representations.

Results: There were 2140 admissions during the review period, comprising 1138 ( 53.2\%) females and 1002 males. The mean new admission per month was 34.55 (M:16.7, F:18.96) with a standard deviation of 7.49 for all admissions. There was a seasonal pattern in admission. Some socio-cultural and environmental factors that may explain the pattern were examined.

Conclusion: This study suggests a seasonal pattern of psychiatric admission in a tertiary health facility in Ibadan. Recommendations were made on how to make use of the knowledge of the seasonal pattern of admission to mitigate disruptions in workload that may be occasioned by the observed pattern.
\end{abstract}

Keywords: Admission, Pattern, Psychiatric, Seasons, Nigeria

\section{INTRODUCTION}

Inpatient care of the mentally ill, though expensive and resource intensive, is still the safest and most effective mode of treatment for patients adjudged unmanageable at home or in the community ${ }^{1}$. Seasonality in utilisation of psychiatric facilities has been observed as far back as the $70 \mathrm{~s}^{2}$ and this observation has not changed till date as recent studies have found monthly variations in psychiatric admissions with a peak around summer or at the peak of local temperature ${ }^{3,4}$. Such audits of psychiatric services including hospital service indices like hospital utilisation index or bed occupancy rates are not a popular research venture in Nigeria. It is possible that there are other place-specific contextual variables that may explain any seasonal pattern of psychiatric admission that may be found in Nigeria. Such findings may improve the preparedness of mental health facilities by guiding service organisation and planning in most sub-Sahara African countries like Nigeria where mental health services are poorly developed and professionals are scarce ${ }^{5}$.

\section{OBJECTIVES}

The study is descriptive in nature and aims to describe the monthly pattern of admissions in the psychiatric ward of a teaching hospital in Nigeria and to examine cultural, environmental and other factors that may influence the pattern.

\section{MATERIALS AND METHODS}

\section{Setting}

The study was conducted at the psychiatry department of University College Hospital, Ibadan, Nigeria between the months of February and March 2009. The psychiatry ward is a 64-bed facility divided into a male and a female wing. The facility principally serves Ibadan and its environs, with a population of close to 5 million; its catchment area, however, is not well defined. The Nursing service unit keeps a monthly admission and discharge register of all patients admitted into the wards. This record contains the sociodemographic data and outcome of all patients. 


\section{Procedure}

Data on monthly admissions over a 5-year period for the two wards, spanning from April 2004 to March 2009 , were extracted from the admission and discharge records kept by the nursing services unit. The data was processed using Microsoft excel and the pattern over the 5-year period was examined using graphical representations.

\section{RESULTS}

There were 2140 admissions during the review period, comprising 1138 (53.2\%) females and 1002 males. The mean new admission per month was 34.55 (M:16.7, F:18.96) with a standard deviation of 7.49 for all admissions. There was a seasonal pattern in admission with a steep build-up in new admissions starting from September through December. The steep rise in representation of the pattern of admission is presented in figs. 1a-e.

\section{DISCUSSION}

This study shows a seasonal pattern of psychiatric admission with a steep build-up in admissions starting from September through January. The only exception was the first year of the review period (Fig. 1a) when the ward was partially closed to new admissions as part of the infection control 'wash down' of the hospital. This finding is similar to the report, from other parts of the world, of higher rates of psychiatric admissions around summer or at the peak of local temperature ${ }^{3,4}$ as the season between the month of September and January in Western Nigeria shares some climatic characteristics with summer period in the western world. For instance, just like may be seen during

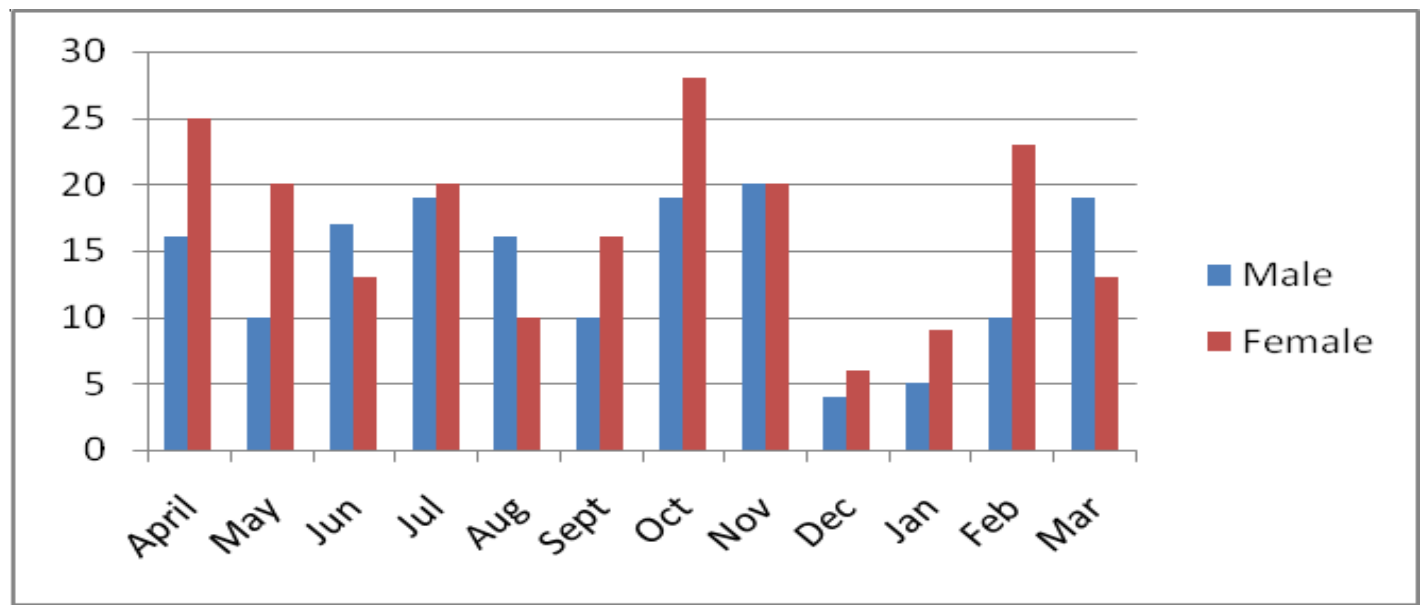

Fig 1a: 2004/05

number of new admissions towards the end of the year appears to reach its peak around December after which it appears to plateau (Figs. 1a-e). At about the month of April the number of new admissions begins to decline reaching a nadir around the month of August before gradually rising again. A graphical summer, Western Nigeria experiences a higher average sunlight hours per day, high daytime temperatures and gradual and steady decline in rainfall between the month of September and January ${ }^{6}$. Therefore one can argue that the climatic and other environmental factors that may underlie the increased psychiatric admissions

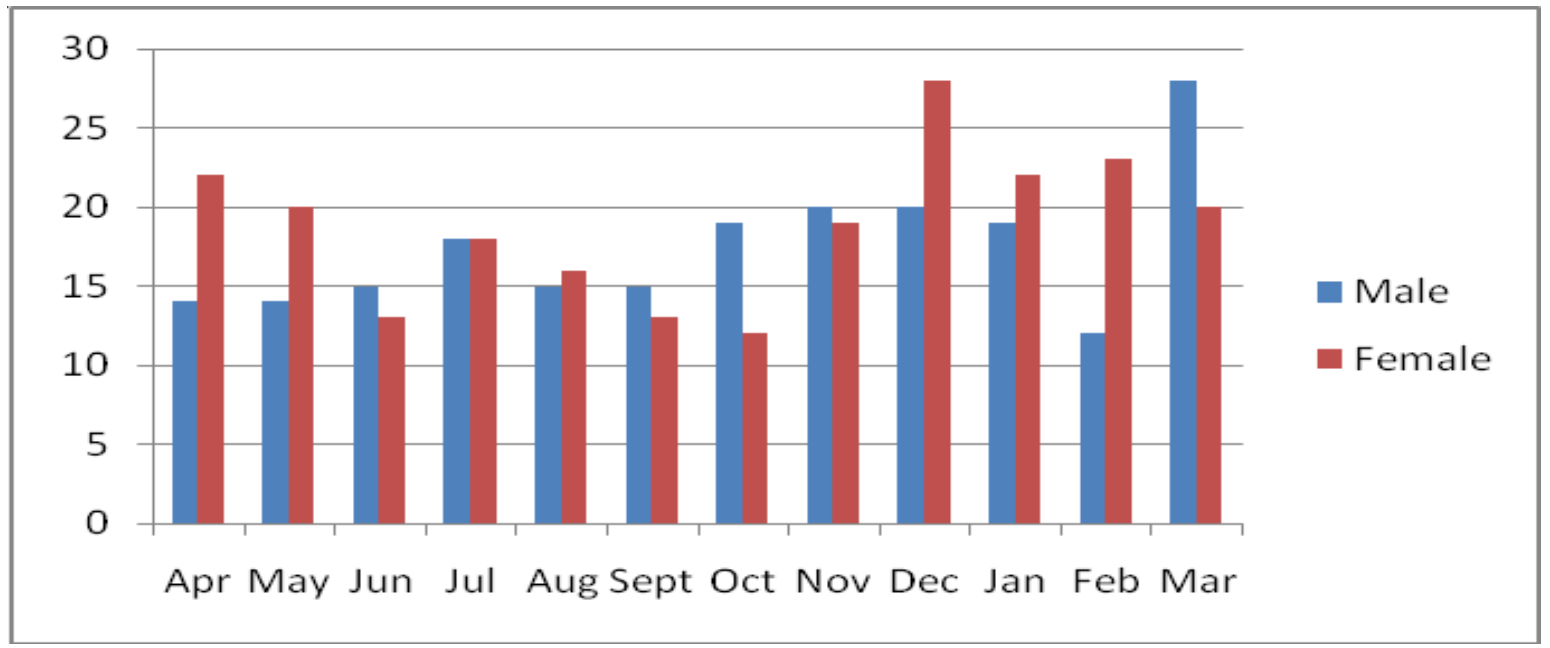

Fig 1b: 2005/06 


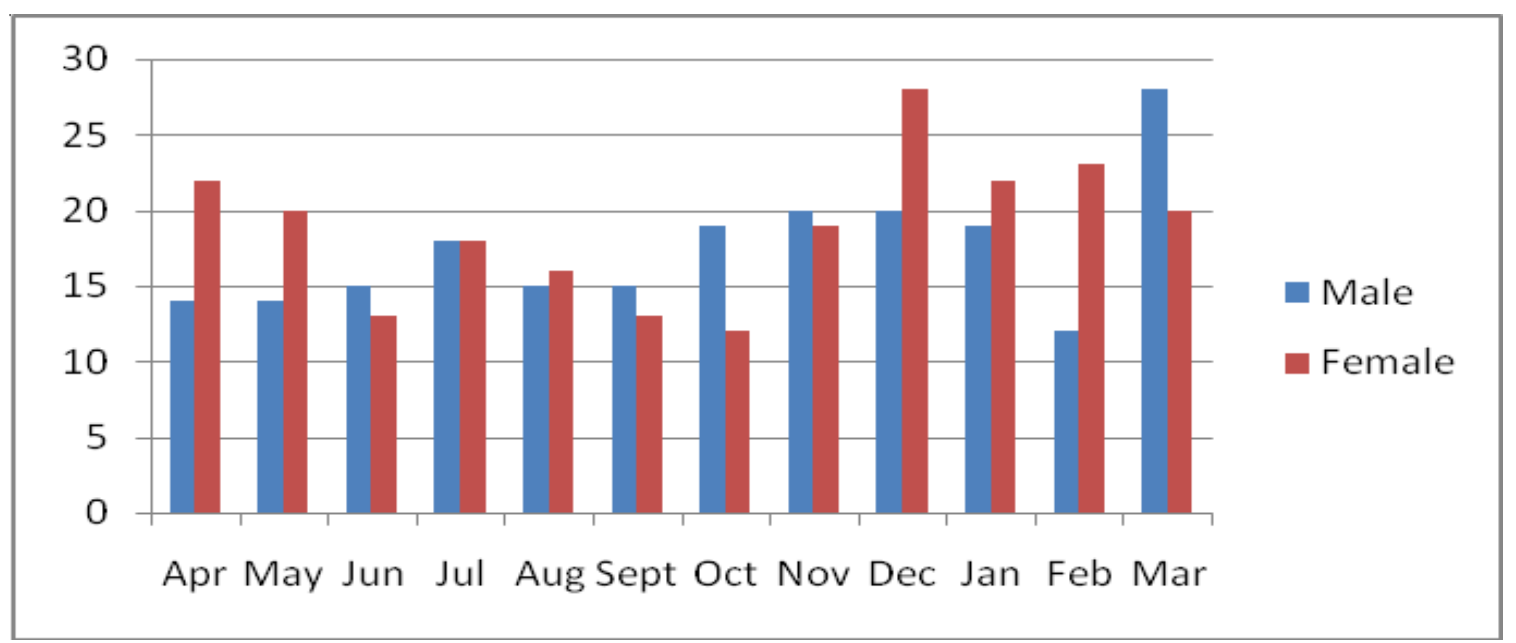

Fig 1c: 2006/07

during summer in the western world may similarly affect Nigerian patients. However, there may be other socio-cultural and economic factors specific for Nigeria that may be contributory.

For instance, because of the general level of socioeconomic development in Nigeria and some other African countries, there is a high level of rural-urban migration among young persons in search of economic and social emancipation ${ }^{7}$. Such youth usually leave their older and more dependent family members supporting orthodox care above other treatment modalities.

Furthermore, the high level of stigma attached to mental illness in this environment ${ }^{8}$ may compel families to bring a mentally ill family member for treatment towards the end of the year merely to keep such patients away from home during the festive periods when they expect to receive a lot of visitors. In addition, the periods between the month of September and January are relatively rain free ${ }^{9}$ and this may improve

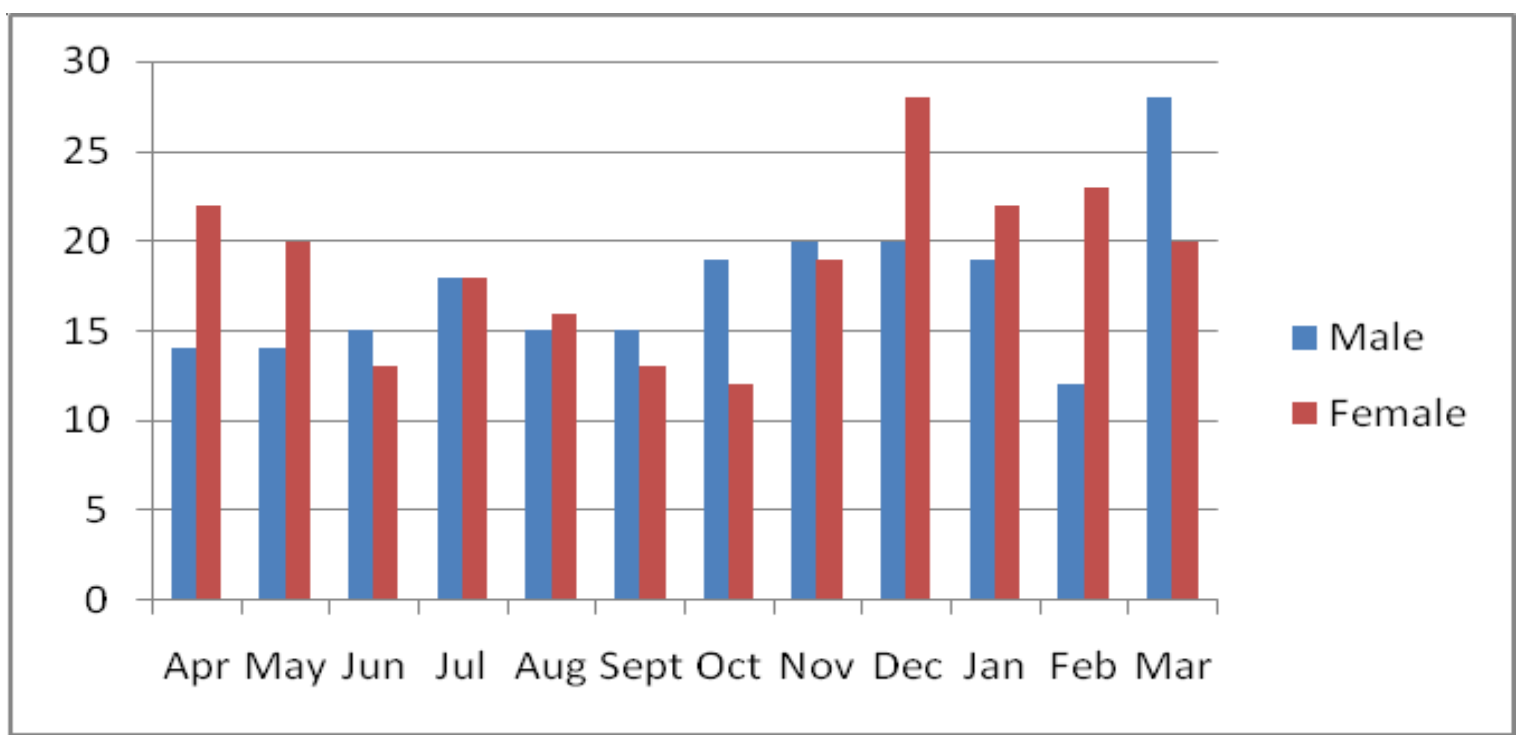

Fig 1d: 2007/08

behind. As it is customary in most parts of Nigeria for such young persons to return home towards the end of the year, more mentally ill patients may be taken to hospital for needed inpatient care. This may be as a result of improved financial or human resources that accompany such returns. The returning family member may also have acquired a better understanding of treatment for mental illness from the cities and thus the pliability of un-tarred roads that leads to most villages in Ibadan and environs, thus reducing the logistics problem of presenting in the hospital. Conversely, the periods between the month of April and early August is the most favourable crop planting season in South-west Nigeria ${ }^{9}$, thus, agricultural activities are usually at its peak about this time, decreasing the level of expendable human resources 
that can be diverted to the care of mentally ill patients. This may partly explain the dip in new admissions observed during the period.

Moreover, Nigerians attach a lot of importance to an individual's financial success at the end of the year. Therefore, a lot of people in this environment may be under increased pressure to garner more financial strength as the year runs to an end and the festive period approaches. This may constitute a special psychosocial stressor that can trigger the onset or relapse of mental illness. Holmes and Harry listed Christmas as a psychosocial stressor in their Social Readjustment Rating Questionnaire ${ }^{10}$, underscoring the psychological relevance of the festive periods.

The seasonal changes in the number of new admissions observed in this study may have implications for patient care. The institute of medicine (IOM) USA, in a report on the issue of nurse staffing and patient care in 2004, concluded that "Research is now beginning to document what physicians, patients, other health care shortage in a health facility in Newcastle, Australia, found that inappropriate roster schedule for current patient load and inability to respond to increased unit activity were the leading cause of shortages in nursing care and the most common consequences of these included problems with drug administration/ documentation, patient supervision and nursing care procedures. Undesirable patient outcomes, according to the study, included major physiological changes, patient/relative dissatisfaction and physical injury. Similar decline in quality of nursing care with increasing workload have been reported in mental health settings ${ }^{16}$.

This study may serve as a basis for recommending that more nurses should be posted to the psychiatric ward during the last three months of the year. Nursing staff may also plan their annual leave not to fall during these periods. However, it is premature to assume that the pattern seen in this study can be generalised for all the regions in the country. There is a need for further studies in this regard.

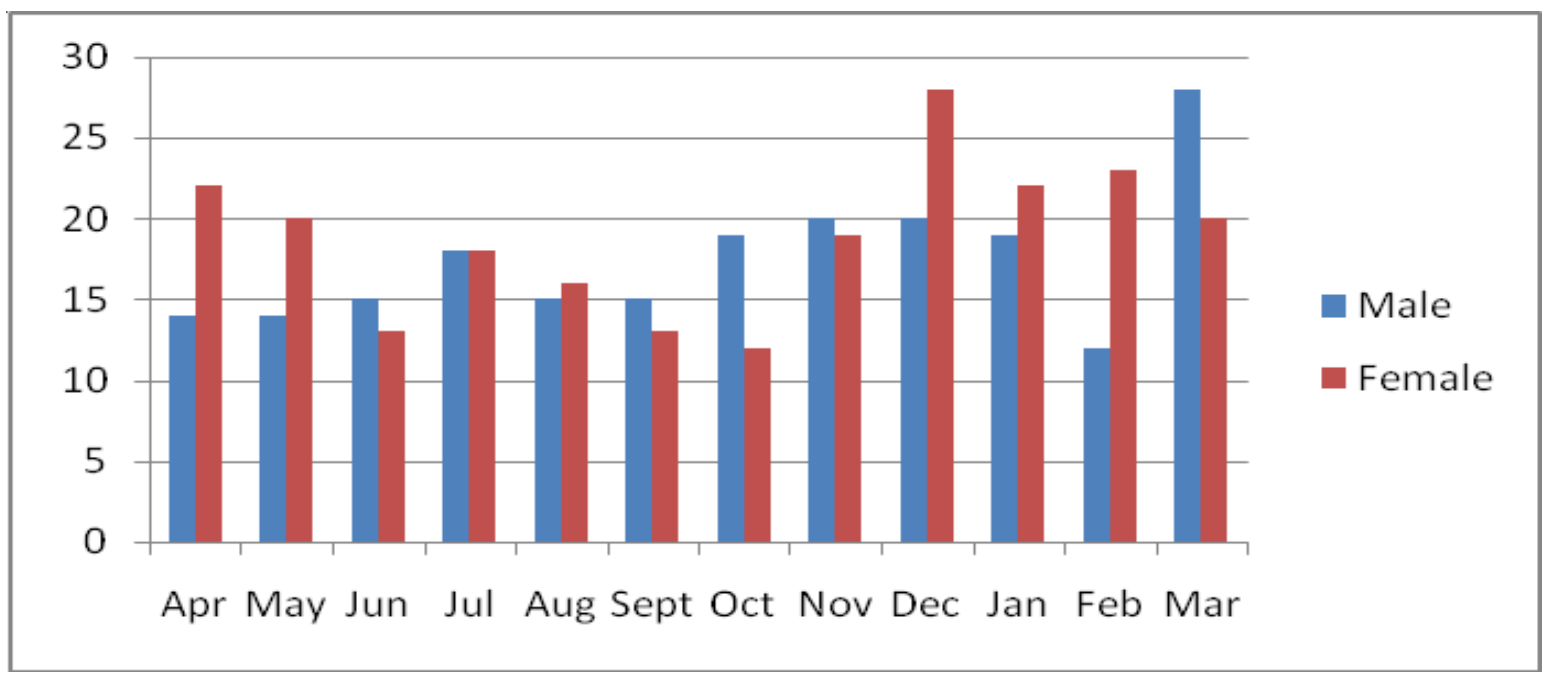

Fig 1e: 2008/09

providers, and nurses themselves have long known: how well we are cared for by nurses affects our health, and sometimes can be a matter of life or death"11. This statement underscores the importance of nursing care in the provision of quality hospital care. In the setting of this study, the number of nurses per shift is usually kept constant irrespective of bed occupancy or pattern of admission. This may then mean a higher work load and Patient: Nurse Ratio during the last 34 months of the year if the observed pattern over the review period is sustained. Studies have shown that quality of nursing care and patients' satisfaction declines with higher Patient: Nurse Ratio ${ }^{12}$ and that this could manifest in higher incidence of patient-safety problems ${ }^{13}$ including deaths ${ }^{14}$. Beckmann et al ${ }^{15}$, while examining the problems associated with nursing staff

\section{CONCLUSION}

This study suggests a seasonal pattern of psychiatric admission in a tertiary health facility in Ibadan. The seasonal pattern may be explained by some sociocultural, economic and environmental factors. It is recommended that nursing roster schedules be made flexible to accommodate consistent annual variations in patterns of psychiatric admissions.

\section{REFERENCES}

1. Bobier C. and Warwick M. Factors associated with readmissions to adolescent psychiatric care. Aust NZL Psychiatry 2005, 39: 600-606

2. Hare $\mathbf{E H}$ and Walter SD. Seasonal variation in admissions of psychiatric patients and its relation 
to seasonal variation in their births. J Epidemiol Community Health 1978; 32(1): 47-52.

3. Singh GP, Chavan BS, Arun P, Sidana A. Seasonal pattern of psychiatry service utilization in a tertiary care hospital. Indian J Psychiatry 2007; 49: 91-95

4. Shiloh R, Shapira A, Potchter O, Hermesh H, Popper M, Weizman A. Effects of climate on admission rates of schizophrenia patients to psychiatric hospitals. Eur Psychiatry 2005; 20:6164.

5. Okasha A. Mental health in Africa; the role of the WPA. World psychiatry 2002; 1, 32-35.

6. http://www.climatetemp.info/nigeria Downloaded on $14^{\text {th }}$ June 2009.

7. Rural-urban interaction in the developing world. (ed) Kenneth Lynch. Routledge Taylor \& Francis Group 2005; Pg 112

8. Gureje O, Lasebikan VO, Ephraim-Oluwanuga $\mathrm{O}$ et al. Community study of knowledge of and attitude to mental illness in Nigeria. The British Journal of Psychiatry 2005; 186: 436-444.

9. Odekunle TO. Rainfall and the length of growing season in Nigeria. International Journal of Climatology 2004; 24:467-469

10. Holmes $\mathbf{T}$ and Rahe R. The Social Readjustment Rating Scale. Journal of Psychosomatic Research 1967; 11: 213-218.
11. IOM, Keeping Patients Safe: Transforming the Work Environment of Nurses. Washington: National Academies Press, 2004

12. Anderson F, Maloney J, Beard L. A descriptive, correlation study of patient satisfaction, provider satisfaction, and provider workload at an army medical centre. Military Medicine 1998; 163, (2);9094

13. Sochalski J. Is More Better? The Relationship Between Nurse Staffing and the Quality of Nursing Care in Hospitals. Medical Care 2004; 42 (2): 67-73

14. Tarnow-Mordi W, Hau C, Warden A, Shearer A. Hospital mortality in relation to staff workload: a 4-year study in an adult intensive-care unit. Lancet 2000; 356 (9225):185-189.

15. Beckmann U, Baldwin I, Durie M, Morrison A, Shaw L. Problems associated with nursing staff shortage: an analysis of the first 3600 incident reports submitted to the Australian Incident Monitoring Study (AIMS-ICU). Anaesth Intensive Care 1998; 26(4): 396-400

16. Ridley C. Relating nursing workload to quality of care in child and adolescent mental health inpatient services. International Journal of Health Care Quality Assurance 2007; 20 (5): 429-440. 